\title{
The Role of Art Elements in the Translation of Photographic Works
}

\section{Peranan Elemen Seni dalam Penterjemahan Karya Fotografi}

\author{
Mohammad Firdaus Azman \\ Fakulti Seni Lukis dan Seni Reka, Universiti Teknologi MARA, Cawangan Perak, \\ Kampus Seri Iskandar, 32610 Seri Iskandar, Perak, MALAYSIA \\ Author email: mfirdz43@gmail.com \\ Published: 7 September 2018
}

\begin{abstract}
ABSTRCT
The presence of photography around the 1890s when Malaya (now Malaysia) which was still under British rule was not an obstacle for the field of photography to grow to this day. Photography is a medium that can be used to produce creative works that have their own artistic elements (Sabki Md. Noh, M. Shariful Hafizal, 2017). The production of the work is produced according to technical procedures that require repeated experimentation to get the best results. Emphasizing the element or line element in the production of a work is none other than to show the relevance of the art element in photography, but also to focus on the use of pattern elements. In the form of social relationships, the artist tries to convey that when filming, visuals should always be taken with care so that every art element that is blended in the production of the work is not overwhelmed or runs away from the original concept. For the artist, this visual is a conversation about what is done as well as what can

be conveyed, in addition to aiming to make the audience aware of the artist's creative process while creating, which illustrates the meaning of the artist's work which usually describes literary language in visual form. With the role of photography that also gives awareness of the importance of understanding the adaptation of visual art elements Keywords: Photography, artistic elements, art work, consciousness
\end{abstract}

\section{ABSTRAK}

Kehadiran fotografi sekitar 1890an tatkala Malaya (kini Malaysia) yang masih lagi dibawah pemerintahan British bukanlah satu halangan untuk bidang fotografi untuk berkembang hingga ke hari ini. Fotografi ialah satu medium yang boleh digunakan untuk menghasilkan karya kreatif yang mempunyai unsur seninya yang tersendiri (Sabki Md. Noh, M. Shariful Hafizal, 2017). Pneghasilan karya dihasilkan mengikut tatacara teknikal yang memerlukan eksperimentasi berulang kali untuk mendapatkan hasil yang terbaik. Menekankan unsur atau elemen garisan (ine) dalam penghasilan karya adalah tidak lain dan tidak bukan untuk menunjukkan kaitan unsur elemen seni dalam fotograf, tetapi juga memberi fokus dalam penggunaan elemen corak (pattern). Dalam bentuk hubungan sosial, artis cuba menyampaikan bahawa ketika melakukan pengambaran, visual perlu sentiasa diambil dengan berhati-hati agar setiap elemen seni yang di adun dalam penghasilan karya tidak ditenggelami mahupun lari dari konsep asal. Bagi artis, visual ini adalah satu bual bicara tentang apa yang dilakukan serta apa yang boleh sampaikan, selain bertujuan menyedarkan audiens mengenai proses kreatif artis ketika berkarya, yang menggambarkan maksud yang dipanggil kerja artis yang biasanya menerangkan bahasa sastera dalam bentuk visual. Dengan peranan fotografi yang juga memberi kesedaran betapa pentingnya memahami adaptasi elemen seni berbentuk visual

Keywords: Fotografi, elemen seni, karya, kesedaran.

eISSN: 2550-214X (C) 2018. The Authors. Published for Idealogy Journal of Arts and Social Science by UiTM Press. This is an Open Access article distributed under the terms of the Creative Commons Attribution-NonCommercial-NoDerivatives License (http://creativecommons.org/licenses/by-nc-nd/4.0/), which permits non-commercial re-use, distribution, and reproduction in any medium, provided the original work is properly cited, and is not altered, transformed, or built upon in any way. 


\section{PENGENALAN}

Kehadiran fotografi sekitar 1890-an tatkala Malaya (kini Malaysia) yang masih lagi dibawah pemerintahan British bukanlah satu halangan untuk bidang fotografi untuk berkembang hingga ke hari ini. Malah, secara realiti kelahiran fotografi pada era British adalah melalui jurugambar salon, yang dasarnya merupakan satu lagi perkataan untuk pameran. Dalam kebanyakan kes, kelab kamera atau masyarakat fotografi mencipta salon mereka dengan beberapa bahagian teras - "warna terbuka" (open colour), "monokrom" (monochrome) dan "alam semula jadi" (nature) (David Candlish, 2015). Hasilnya, ramai konvensyen yang diketengahkan oleh jurugambar salon pada masa lalu terus relevan hari ini (Zhuang Wubin, 2016) dan ia telah membawa dimensi baru dalam bidang fotografi di Malaysia.

\section{ADAPTASI ELEMEN}

Fotografi ialah satu medium yang boleh digunakan untuk menghasilkan karya kreatif yang mempunyai unsur seninya yang tersendiri (Sabki Md. Noh, M. Shariful Hafizal, 2017). Elemen seni rekabentuk boleh dengan mudah dimasukkan ke dalam imej sebagai jenis cetak biru (blueprint) yang tidak dapat diselesaikan untuk menghasilkan struktur yang menyokong daya tarikan atau kuasa komposisi (Jeremy Webb, 2010). Putaran Api (Gambar 1.1) dihasilkan mengikut tatacara teknikal yang memerlukan eksperimentasi berulang kali untuk mendapatkan hasil yang terbaik. Menekankan unsur atau elemen garisan (line) dalam penghasilan karya ini adalah tidak lain dan tidak bukan untuk menunjukkan kaitan unsur elemen seni dalam fotografi. Karya ini juga memberi penjelasan mudah (simplify) tentang apa yang ingin disampaikan (expression) oleh pengkarya, apatah lagi dalam seni visual, penggunaan garisan mungkin merupakan elemen paling penting dalam reka bentuk (Jeremy Webb, 2010).

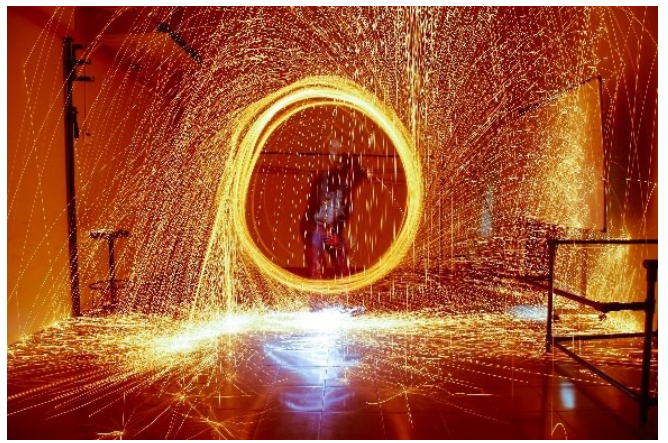

Figure 1: Putaran Api.

Source: Mohammad Firdaus Azman. (2018)

\section{PERSPEKTIF KARYA NATURALIS HUTAN ROYAL BELUM}

Setiap pengembaraan habitat semulajadi tidak akan terpisah dengan memori yang tersendiri. Dalam fotografi, rakaman setiap detik ketika berada di dalam "zon hijau" adalah satu "moment", apatah lagi ia adalah satu ramuan yang tidak asing lagi dalam mengadaptasi dan mengubah setiap subjek "nature" ke dalam bentuk visual. Penterjemahan setiap visual adalah intipati luahan individu yang mempunyai idea yang tersendiri dalam pembikinan karya berbentuk fotografi. Subjek di dalam visual ini adalah satu anyaman dinding sebuah pondok di dalam kawasan Hutan Royal Belum, yang merupakan salah satu daripada hutan hujan tertua di dunia, sejak lebih 130 juta tahun (Wonderful Malaysia, 2007-2017) yang terletak di negeri Perak, Malaysia. 


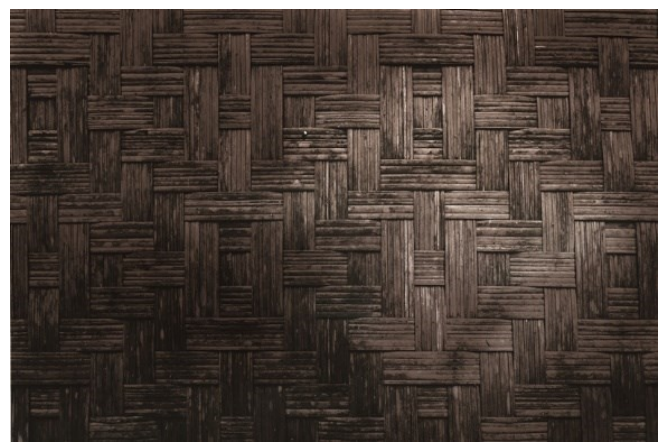

Figure 2: Fotografi Abstrak Seni Anyaman Dinding Rumah. Source: Mohammad Firdaus Azman. (2015)

Fotografi Abstrak Seni Anyaman Dinding Rumah (Gambar 1.2) merupakan satu lagi karya visual yang cuba menterjemahkan bukan sahaja berkenaan dengan teknik tradisional masyarakat orang asli dalam menghasilkan kraf terutama sekali dalam senibina dimana mereka menggunakan sumber alam untuk mendirikan struktur rumah mereka yang dikelilingi dengan ribuan sumber alam, tetapi juga memberi fokus dalam penggunaan elemen corak (pattern). Penekanan elemen ini mempengaruhi cara penyampai mesej oleh artis kerana ia memperkuat pemahaman kita tentang satu elemen dengan mempunyai kuasa diperkuatkan; ia juga memberikan kepastian emosi, yang boleh memberi jaminan (Jeremy Webb, 2010). Secara teknikal visual ini dirakam menggunakan DSLR sebelum ia diolah menggunakan teknik "Duotone" bagi menampakkan tema klasik dalam visual tersebut

\section{KESIMPULAN}

Dalam bentuk hubungan sosial, artis cuba menyampaikan bahawa ketika melakukan pengambaran, visual perlu sentiasa diambil dengan berhati-hati agar setiap elemen seni yang di adun dalam penghasilan karya tidak ditenggelami mahupun lari dari konsep asal. Bagi artis, visual ini adalah satu bual bicara tentang apa yang dilakukan serta apa yang boleh sampaikan, selain bertujuan menyedarkan audiens mengenai proses kreatif artis ketika berkarya, yang menggambarkan maksud yang dipanggil kerja artis yang biasanya menerangkan bahasa sastera dalam bentuk visual. Dengan peranan fotografi yang juga memberi kesedaran betapa pentingnya memahami adaptasi elemen seni berbentuk visual, walapupun kini cabaran untuk menghasilkan karya fotografi samada dalam teknik tradisional (filem) yang kini kian tenggelam timbul ditelan zaman teknologi (digital), menjadi usang, dan digantikan dengan yang baru, tetapi kreativiti dalam memenuhi citarasa penyampaian isi tersirat amatlah luas.Selain itu, intipati kandungan (content) serta subjek juga memberi "influence" tersendiri dalam fotografi. Subjek bukanlah matlamat, ia adalah suatu kesatuan baru, lyricism yang tumbuh sepenuhnya daripada cara-cara (Georges Braque, 1958).

Gambar-gambar yang menjadi saksi kepada fakta-fakta, sama ada yang boleh dilihat atau kewujudan, dan ia adalah satu fakta bahawa hubungan kita dengan alam semula jadi adalah satu yang bermasalah yang tidak boleh menjadi sebaliknya di bawah dispensasi budaya ini. (Frank Gohlke, 2011) Keprihatinan dalam membina sesuatu karya bukanlah satu permulaan yang mudah kerana seni fotografi adalah seperti ungkapan, dari segi abstrak, emosi dan menyatakan kesedaran (Louise Bourgeois, 1954).

Namun begitu perlu diingat bahawa tiada jalan yang betul mahupun salah ketika menghasilkan sesuatu karya fotografi, ianya terpulang kepada niat (intention) seseorang pengkarya itu dalam menghasilkan kerjanya (work).

Seseorang jurugambar sering mendapati bahawa walaupun mereka sentiasa menguji had dan sempadan kesedaran reka bentuk mereka sendiri, komitmen mereka terhadap proses reka bentuk hanya menjadi dalaman dan aliran, dan sekali anda boleh mendekati fotografi anda dengan yakin yang datang dari pengetahuan ini, membolehkan fotografi anda untuk menjadi dibebaskan, spontan dan sangat kreatif (Jeremy Webb, 2010). 


\section{RUJUKAN}

Bourgeois, L. (1954). Louise Bourgeois Artist's Statement. Reading Abstract Expressionism: Context and Critique, 18. Retrieved from http://timothyquigley.net.

Candlish, D. (2015, April 14). David Candlish Photography. Retrieved from David Candlish Photography Web Site: http://davidcandlish.photography/news/2015/4/13/a- beginners-guide-tothe-world-of-photography-salons

Houben, I. (2007-2017). Wonderful Malaysia. Retrieved from Wonderful Malaysia Web Site: http://www.wonderfulmalaysia.com/royal-belum-state-park-malaysia.htm

Pensum. (2011, January 03). Artist Statements. Retrieved from Artist Statements: An Archive: https://artiststatements.wordpress.com/2011/01/03/frank-gohlke- thoughts-on-landscape/

Pensum. (2011, October 14). Artist Statements. Retrieved from Artist Statements: An Archive: https://artiststatements.wordpress.com/2011/10/14/georges-braque- thoughts-and-reflections-onpainting/

Sabki Md. Noh, M. S. (2017). Panduan Asas fotografi Digital. Kuala Lumpur: Dewan Bahasa dan Pustaka.

Webb, J. (2010). Basics Creative Photography 01: Design Principles. Lausanne: AVA Publishing. Wubin, Z. (2016). Photography in Southeast Asia. Singapore: NUS Press. 